\title{
Existence and Uniqueness of Solution to Nonlinear Boundary Value Problems with Sign-Changing Green's Function
}

\author{
Peiguo Zhang, ${ }^{1}$ Lishan Liu, ${ }^{2}$ and Yonghong $\mathrm{Wu}^{3}$ \\ ${ }^{1}$ Department of Mathematics, Heze University, Heze, Shandong 274000, China \\ ${ }^{2}$ School of Mathematical Sciences, Qufu Normal University, Qufu, Shandong 273165, China \\ ${ }^{3}$ Department of Mathematics and Statistics, Curtin University of Technology, Perth, WA 6845, Australia
}

Correspondence should be addressed to Peiguo Zhang; zhangpeiguo@163.com

Received 20 July 2013; Accepted 23 August 2013

Academic Editor: Shaoyong Lai

Copyright (C) 2013 Peiguo Zhang et al. This is an open access article distributed under the Creative Commons Attribution License, which permits unrestricted use, distribution, and reproduction in any medium, provided the original work is properly cited.

By using the cone theory and the Banach contraction mapping principle, the existence and uniqueness results are established for nonlinear higher-order differential equation boundary value problems with sign-changing Green's function. The theorems obtained are very general and complement previous known results.

\section{Introduction}

Boundary value problems (BVPs for short) for nonlinear differential equations arise in a variety of areas of applied mathematics, physics, and variational problems of control theory. The study of multipoint BVPs for second-order differential equations was initiated by Bicadze and Samarskii [1] and later continued by II'in and Moiseev [2,3] and Gupta [4]. Since then, great efforts have been devoted to nonlinear multipoint BVPs due to their theoretical challenge and great application potential. Many results on the existence of solutions for multipoint BVPs have been obtained; the methods used therein mainly depend on the fixed point theorems, degree theory, upper and lower techniques, and monotone iteration. The existence results are available in the literature [5-25] and the references therein.

Recently, by applying the fixed point theorems on cones, the authors of papers [5-7] established the existence and multiplicity of positive solutions for the $n$ th-order three-point BVP:

$$
\begin{gathered}
u^{(n)}(t)+a(t) f(t, u(t))=0, \quad t \in(0,1), \\
u(0)=u^{\prime}(0)=\cdots=u^{(n-2)}(0)=0, \quad u(1)=\alpha u(\eta),
\end{gathered}
$$

where $n \leq 2,0<\eta<1$ and $0<\alpha \eta^{n-1}<1$. The $n$ th-order $m$-point BVP

$$
\begin{gathered}
u^{(n)}(t)+a(t) f(t, u(t))=0, \quad t \in(0,1), \\
u(0)=u^{\prime}(0)=\cdots=u^{(n-2)}(0)=0, \quad u(1)=\sum_{i=1}^{m-2} \alpha_{i} u\left(\eta_{i}\right)
\end{gathered}
$$

has been studied in [8-10], where $n \geq 2,0<\eta_{1}<\eta_{2}<$ $\cdots \eta_{m-2}<1$ and $\alpha_{i}>0(i=1,2, \ldots, m-2)$ with $0<$ $\sum_{i=1}^{m-2} \alpha_{i} \eta_{i}^{n-1}<1$. The existence and multiplicity results of solutions were shown by using various fixed point theorems and fixed point index theory.

By using the cone theory and the Banach contraction mapping principle, the author [26] established the existence and uniqueness for singular third-order three-point boundary value problems.

The purpose of this paper is to investigate the existence and uniqueness of solution of the following higher-order differential equation boundary value problem:

$$
\begin{gathered}
u^{(n)}(t)+f\left(t, u(t), u^{\prime}(t), \ldots, u^{(n-1)}(t)\right)=0, \quad t \in J, \\
u(0)=u^{\prime}(0)=\cdots=u^{(n-2)}(0)=0, \quad u(1)=\sum_{i=1}^{m-2} \alpha_{i} u\left(\eta_{i}\right),
\end{gathered}
$$


where $n \geq 2, f \in C\left(J \times \mathbb{R}^{n}, \mathbb{R}\right), J=(0,1), \sum_{i=1}^{m-2} \alpha_{i} \eta_{i}^{n-1}$ $\neq 1$, and $0<\eta_{1}<\cdots<\eta_{m-2}<1$.

Here, we give the unique solution of BVP (3) under the conditions that $f$ is mixed nonmonotone. The methods used in this paper are motivated by [26], and the arguments are based upon the cone theory and the Banach contraction mapping principle.

\section{The Preliminary Lemmas}

Lemma 1. For any $f \in L(I)$, the $B V P$

$$
\begin{gathered}
u^{\prime}(t)+f(t)=0, \quad t \in J, \\
\int_{0}^{1}(1-t)^{n-2} u(t) d t=\sum_{i=1}^{m-2} \alpha_{i} \int_{0}^{\eta_{i}}\left(\eta_{i}-t\right)^{n-2} u(t) d t
\end{gathered}
$$

has a unique solution $u(t)=\int_{0}^{1} G(t, s) f(s) d s$, where

$$
\begin{aligned}
& G(t, s)=\left\{\begin{array}{c}
-1+\frac{1}{\sigma}\left[(1-s)^{n-1}-\sum_{i=1}^{m-2} \alpha_{i}\left(\eta_{i}-s\right)^{n-1}\right], \\
0 \leq s \leq \eta_{1}, s \leq t, \\
\frac{1}{\sigma}\left[(1-s)^{n-1}-\sum_{i=1}^{m-2} \alpha_{i}\left(\eta_{i}-s\right)^{n-1}\right], \\
0 \leq t \leq s \leq \eta_{1}, \\
-1+\frac{1}{\sigma}\left[(1-s)^{n-1}-\sum_{i=j+1}^{m-2} \alpha_{i}\left(\eta_{i}-s\right)^{n-1}\right], \\
\eta_{j} \leq s \leq \eta_{j+1}, \quad s \leq t, \\
\frac{1}{\sigma}\left[(1-s)^{n-1}-\sum_{i=j+1}^{m-2} \alpha_{i}\left(\eta_{i}-s\right)^{n-1}\right], \\
\eta_{j} \leq s \leq \eta_{j+1}, \quad t \leq s, \\
-1+\frac{(1-s)^{n-1},}{\eta_{m-2}} \leq s \leq t \leq 1, \\
\frac{(1-s)^{n-1}}{\sigma}, \\
\eta_{m-2} \leq s \leq 1, t \leq s,
\end{array}\right. \\
& \sigma=1-\sum_{i=1}^{m-2} \alpha_{i} \eta_{i}^{n-1}, \quad I=[0,1] .
\end{aligned}
$$

Proof. First, suppose that $u \in C(I)$ is a solution to problem (4) and (5). It is easy to see by integration of (4) that

$$
u(t)=u(0)-\int_{0}^{t} f(s) d s
$$

Substituting (7) into (5), we obtain

$$
\begin{aligned}
\int_{0}^{1}(1-t)^{n-2}\left[u(0)-\int_{0}^{t} f(s) d s\right] d t \\
\quad=\sum_{i=1}^{m-2} \alpha_{i} \int_{0}^{\eta_{i}}\left(\eta_{i}-t\right)^{n-2}\left[u(0)-\int_{0}^{t} f(s) d s\right] d t,
\end{aligned}
$$

and so

$$
\begin{aligned}
& u(0)=\left[\int_{0}^{1}(1-t)^{n-2} d t-\sum_{i=1}^{m-2} \alpha_{i} \int_{0}^{\eta_{i}}\left(\eta_{i}-t\right)^{n-2} d t\right]^{-1} \\
& \times\left[\int_{0}^{1}(1-t)^{n-2} \int_{0}^{t} f(s) d s d t\right. \\
& \left.-\sum_{i=1}^{m-2} \alpha_{i} \int_{0}^{\eta_{i}}\left(\eta_{i}-t\right)^{n-2} \int_{0}^{t} f(s) d s d t\right] \\
& =\left(\frac{1-\sum_{i=1}^{m-2} \alpha_{i} \eta_{i}^{n-1}}{n-1}\right)^{-1} \\
& \times\left[\int_{0}^{1}(1-t)^{n-2} \int_{0}^{t} f(s) d s d t\right. \\
& \left.-\sum_{i=1}^{m-2} \alpha_{i} \int_{0}^{\eta_{i}}\left(\eta_{i}-t\right)^{n-2} \int_{0}^{t} f(s) d s d t\right] \\
& =\frac{n-1}{\sigma}\left[\int_{0}^{1}(1-t)^{n-2} \int_{0}^{t} f(s) d s d t\right. \\
& \left.-\sum_{i=1}^{m-2} \alpha_{i} \int_{0}^{\eta_{i}}\left(\eta_{i}-t\right)^{n-2} \int_{0}^{t} f(s) d s d t\right] \\
& =\frac{n-1}{\sigma}\left[\int_{0}^{1} f(s) \int_{s}^{1}(1-t)^{n-2} d t d s\right. \\
& \left.-\sum_{i=1}^{m-2} \alpha_{i} \int_{0}^{\eta_{i}} f(s) \int_{s}^{\eta_{i}}\left(\eta_{i}-t\right)^{n-2} d t d s\right] \\
& =\frac{1}{\sigma}\left[\int_{0}^{1} f(s)(1-s)^{n-1} d s\right. \\
& \left.-\sum_{i=1}^{m-2} \alpha_{i} \int_{0}^{\eta_{i}} f(s)\left(\eta_{i}-s\right)^{n-1} d s\right] .
\end{aligned}
$$

Substituting (9) into (7), we have

$$
\begin{aligned}
u(t)= & -\int_{0}^{t} f(s) d s \\
& +\frac{1}{\sigma}\left[\int_{0}^{1} f(s)(1-s)^{n-1} d s\right. \\
& \left.\quad-\sum_{i=1}^{m-2} \alpha_{i} \int_{0}^{\eta_{i}} f(s)\left(\eta_{i}-s\right)^{n-1} d s\right] \\
= & \int_{0}^{1} G(t, s) f(s) d s .
\end{aligned}
$$

Conversely, suppose that $u(t)=\int_{0}^{1} G(t, s) f(s) d s$; then it is easy to verify that (4) and (5) are satisfied. The lemma is proved. 
For any $u \in C(I)$, let

$$
\begin{gathered}
\left(I_{i} u\right)(t)=\int_{0}^{t} \frac{(t-s)^{i-1}}{(i-1) !} u(s) d s, \quad i=1,2, \ldots, n-1, \\
(F u)(t)=\int_{0}^{1} G(t, s) f\left(s,\left(I_{n-1} u\right)(s), \ldots,\right. \\
\left.\left(I_{1} u\right)(s), u(s)\right) d s, \quad t \in I .
\end{gathered}
$$

Lemma 2. (i) If $u \in C^{n-1}(I)$ is a solution to problem (3), then $v(t)=u^{(n-1)}(t) \in C(I)$ is a fixed point of $F$.

(ii) If $v \in C(I)$ is a fixed point of $F$, then $u(t)=\left(I_{n-1} v\right)(t)=$ $\int_{0}^{t}\left((t-s)^{n-2} /(n-2) !\right) v(s) d s \in C^{n-1}(I)$ is a solution to problem (3).

By Lemma 1, the proof follows by routine calculations. Let

$$
\begin{gathered}
h_{1}(t)=\max \left\{\int_{0}^{1}|G(t, s)| d s, \int_{0}^{t} \int_{0}^{1}|G(s, x)| d x d s\right\}, \\
h_{k}(t)=\max \left\{\int_{0}^{1}|G(t, s)| h_{k-1}(s) d s,\right. \\
\left.\int_{0}^{t} \int_{0}^{1}|G(s, x)| h_{k-1}(x) d x d s\right\}, \\
k=2,3, \ldots, \\
\rho(G)=\lim _{k \rightarrow \infty}\left(\operatorname{suph}_{t \in J}(t)\right)^{-1 / k} .
\end{gathered}
$$

It is easy to see that $\rho(G) \geq\left(\sup _{t \in J} h_{k}(t)\right)^{-1 / k} \geq$ $\left(\sup _{t, s \in J}|G(t, s)|\right)^{-1}>0$.

Lemma 3 (see $[27,28]$ ). $P$ is a generating cone in Banach space $(E,\|\cdot\|)$ if and only if there exists a constant $\tau>0$ such that every element $u \in E$ can be represented in the form $u=v-w$, where $v, w \in P$ and $\|v\| \leq \tau\|u\|,\|w\| \leq \tau\|u\|$.

\section{Main Results}

This section discusses the solution of nonlinear higher-order differential equation BVP (3).

Let $P=\{u \in C(I) \mid u(t) \geq 0$, for all $t \in[0,1]\}$. Obviously, $P$ is a normal solid cone of Banach space $C(I)$, by Lemma 2.1.2 in [29], and we have that $P$ is a generating cone in $C(I)$.

Theorem 4. Suppose that $g \in C\left(J \times \mathbb{R}^{2 n}, \mathbb{R}\right), f\left(t, x_{0}, x_{1}, \ldots\right.$, $\left.x_{n-1}\right)=g\left(t, x_{0}, x_{0}, x_{1}, x_{1}, \ldots, x_{n-1}, x_{n-1}\right)$, and there exist positive constants $K_{0}, M_{0}, K_{1}, M_{1}, \ldots, K_{n-1}, M_{n-1}$ with

$$
\begin{aligned}
\frac{K_{0}+M_{0}}{(n-1) !} & +\frac{K_{1}+M_{1}}{(n-2) !}+\cdots+\frac{K_{n-3}+M_{n-3}}{2 !}+K_{n-2} \\
& +M_{n-2}+K_{n-1}+M_{n-1}<\rho(G)
\end{aligned}
$$

such that for any $t \in I, s_{01}, t_{01}, s_{02}, t_{02}, s_{11}, t_{11}, s_{12}, t_{12}$, $\ldots, s_{1, n-1}, t_{1, n-1}, s_{2, n-1}, t_{2, n-1} \in \mathbb{R}$ with $s_{01} \leq t_{01}, s_{02} \geq$ $t_{02}, s_{11} \leq t_{11}, s_{12} \geq t_{12}, \ldots, s_{n-1,1} \leq t_{n-1,1}, s_{n-1,2} \geq t_{n-1,2}$, one has

$$
\begin{aligned}
& -K_{0}\left(t_{01}-s_{01}\right)-M_{0}\left(s_{02}-t_{02}\right)-K_{1}\left(t_{11}-s_{11}\right) \\
& -M_{1}\left(s_{12}-t_{12}\right)-\cdots-K_{n-1}\left(t_{n-1,1}-s_{n-1,1}\right) \\
& -M_{n-1}\left(s_{n-1,2}-t_{n-1,2}\right) \\
& \leq-g\left(t, s_{01}, s_{02}, s_{11}, s_{12}, \ldots, s_{n-1,1}, s_{n-1,2}\right) \\
& \quad-g\left(t, t_{01}, t_{02}, t_{11}, t_{12}, \ldots, t_{n-1,1}, t_{n-1,2}\right) \\
& \leq-K_{0}\left(t_{01}-s_{01}\right)-M_{0}\left(s_{02}-t_{02}\right)-K_{1}\left(t_{11}-s_{11}\right) \\
& \quad-M_{1}\left(s_{12}-t_{12}\right)-\cdots-K_{n-1}\left(t_{n-1,1}-s_{n-1,1}\right) \\
& \quad-M_{n-1}\left(s_{n-1,2}-t_{n-1,2}\right),
\end{aligned}
$$

and there exist $u_{0}, v_{0} \in C^{n-1}(I)$, such that

$$
\begin{gathered}
\int_{0}^{1} g\left(t, u_{0}(t), v_{0}(t), u_{0}^{\prime}(t), v_{0}^{\prime}(t), \cdots,\right. \\
\left.u_{0}^{(n-1)}(t), v_{0}^{(n-1)}(t)\right) d t
\end{gathered}
$$

converges. Then, BVP (3) has a unique solution $I_{n-1} u^{*}$ in $C(I)$, and moreover, for any $u_{0} \in C(I)$, the iterative sequence

$$
\begin{array}{r}
u_{m}(t)=\int_{0}^{1} G(t, s) f\left(s,\left(I_{n-1} u_{m-1}\right)(s), \ldots,\right. \\
\left.\left(I_{1} u_{m-1}\right)(s), u_{m-1}(s)\right) d s, \\
m=1,2, \ldots,
\end{array}
$$

converges to $u^{*}$ in $C(I)(m \rightarrow \infty)$.

Remark 5. Recently, in the study of BVP (3), almost all the papers have supposed that Green's function $G(t, s)$ is nonnegative. However, the scope of $\alpha_{i}$ is not limited to $\sum_{i=1}^{m-2} \alpha_{i} \eta_{i}<1$ in Theorem 4, so, we do not need to suppose that $G(t, s)$ is nonnegative.

Remark 6. The function $f$ in Theorem 4 is not monotone or convex; the conclusions and the proof used in this paper are different from the known papers in essence.

Proof of Theorem 4. It is easy to see that, for any $t \in J, G(t, s)$ can be divided into finite partitioned monotone and bounded function on $(0,1)$, and then, by (15), we have that

$$
\begin{gathered}
\int_{0}^{1} G(t, s) g\left(s, u_{0}(s), v_{0}(s), u_{0}^{\prime}(s), v_{0}^{\prime}(s), \ldots\right. \\
\left.u_{0}^{(n-1)}(s), v_{0}^{(n-1)}(s)\right) d s
\end{gathered}
$$

converges. Let $p(t)=u_{0}^{(n-1)}(t), q(t)=v_{0}^{(n-1)}(t)$; then

$$
\begin{array}{r}
\int_{0}^{1} G(t, s) g\left(s,\left(I_{n-1} p\right)(s),\left(I_{n-1} q\right)(s), \ldots\right. \\
\left.\left(I_{1} p\right)(s),\left(I_{1} q\right)(s), p(t), q(s)\right) d s
\end{array}
$$

converges. 
For any $u, v \in C(I)$, let $x(t)=|p(t)|+|u(t)|, y(t)=$ $-|q(t)|-|v(t)|$ and then $x \geq p, y \leq q$. By (14), we have

$$
\begin{aligned}
& -K_{0}\left(I_{n-1} x-I_{n-1} p\right)(t)-M_{0}\left(I_{n-1} q-I_{n-1} y\right)(t) \\
& -K_{1}\left(I_{n-2} x-I_{n-2} p\right)(t)-M_{1}\left(I_{n-2} q-I_{n-2} y\right)(t) \\
& -\cdots-K_{n-2}\left(I_{1} x-I_{1} p\right)(t)-M_{n-2}\left(I_{1} q-I_{1} y\right)(t) \\
& -K_{n-1}(x-p)(t)-M_{n-1}(q-y)(t) \\
& \leq g\left(t,\left(I_{n-1} x\right)(t),\left(I_{n-1} y\right)(t), \ldots,\right. \\
& \left.\quad\left(I_{1} x\right)(t),\left(I_{1} y\right)(t), x(t), y(t)\right) \\
& \quad-g\left(t,\left(I_{n-1} p\right)(t),\left(I_{n-1} q\right)(t), \ldots,\right. \\
& \left.\quad\left(I_{1} p\right)(t),\left(I_{1} q\right)(t), p(t), q(t)\right) \\
& \leq K_{0}\left(I_{n-1} x-I_{n-1} p\right)(t)+M_{0}\left(I_{n-1} q-I_{n-1} y\right)(t) \\
& +K_{1}\left(I_{n-2} x-I_{n-2} p\right)(t)+M_{1}\left(I_{n-2} q-I_{n-2} y\right)(t) \\
& +\cdots+K_{n-2}\left(I_{1} x-I_{1} p\right)(t)+M_{n-2}\left(I_{1} q-I_{1} y\right)(t) \\
& +K_{n-1}(x-p)(t)+M_{n-1}(q-y)(t) .
\end{aligned}
$$

Hence,

$$
\begin{aligned}
\mid G(t, s) g\left(t,\left(I_{n-1} x\right)(t),\left(I_{n-1} y\right)(t), \ldots,\right. & \left.\left(I_{1} x\right)(t),\left(I_{1} y\right)(t), x(t), y(t)\right) \\
-G(t, s) g\left(t,\left(I_{n-1} p\right)(t),\left(I_{n-1} q\right)(t), \ldots,\right. & \left.\left(I_{1} p\right)(t),\left(I_{1} q\right)(t), p(t), q(t)\right) \mid \\
\leq|G(t, s)|[ & K_{0}\left|\left(I_{n-1} x\right)(t)-\left(I_{n-1} p\right)(t)\right| \\
+ & M_{0}\left|\left(I_{n-1} q\right)(t)-\left(I_{n-1} y\right)(t)\right| \\
+ & K_{1}\left|\left(I_{n-2} x\right)(t)-\left(I_{n-2} p\right)(t)\right| \\
+ & M_{1}\left|\left(I_{n-2} q\right)(t)-\left(I_{n-2} y\right)(t)\right| \\
+ & \cdots+K_{n-2}\left|\left(I_{1} x\right)(t)-\left(I_{1} p\right)(t)\right| \\
& +M_{n-2}\left|\left(I_{1} q\right)(t)-\left(I_{1} y\right)(t)\right| \\
+ & \left.K_{n-1}|x(t)-p(t)|+M_{n-1}|q(t)-y(t)|\right] \\
\leq|G(t, s)|[ & \left(K_{0}+K_{1}+\cdots+K_{n-1}\right)\|x-p\| \\
+ & \left.\left(M_{0}+M_{1}+\cdots+M_{n-1}\right)\|q-y\|\right] .
\end{aligned}
$$

Following the former inequality, we can easily have that

$$
\begin{aligned}
\int_{0}^{1} G(t, s)\left[g \left(s,\left(I_{n-1} x\right)(s),\left(I_{n-1} y\right)(s), \ldots,\right.\right. \\
\left.\left(I_{1} x\right)(s),\left(I_{1} y\right)(s), x(s), y(s)\right) \\
-g\left(s,\left(I_{n-1} p\right)(s),\left(I_{n-1} q\right)(s), \ldots,\right. \\
\left.\left.\left(I_{1} p\right)(s),\left(I_{1} q\right)(s), p(s), q(s)\right)\right] d s
\end{aligned}
$$

converges, thus,

$$
\begin{aligned}
& \int_{0}^{1} G(t, s) g\left(s,\left(I_{n-1} x\right)(s),\left(I_{n-1} y\right)(s), \ldots,\right. \\
& \left.\left(I_{1} x\right)(s),\left(I_{1} y\right)(s), x(s), y(s)\right) d s \\
& =\int_{0}^{1} G(t, s) g\left(s,\left(I_{n-1} p\right)(s),\left(I_{n-1} q\right)(s), \ldots,\right. \\
& \left.\left(I_{1} p\right)(s),\left(I_{1} q\right)(s), p(s), q(s)\right) d s \\
& +\int_{0}^{1} G(t, s)\left[g \left(s,\left(I_{n-1} x\right)(s),\left(I_{n-1} y\right)(s), \ldots,\right.\right. \\
& \left.\left(I_{1} x\right)(s),\left(I_{1} y\right)(s), x(s), y(s)\right) \\
& -g\left(s,\left(I_{n-1} p\right)(s),\left(I_{n-1} q\right)(s), \ldots,\right. \\
& \left.\left.\left(I_{1} p\right)(s),\left(I_{1} q\right)(s), p(s), q(s)\right)\right] d s
\end{aligned}
$$

is converged.

Similarly, by $x \geq u, y \leq v$,

$$
\begin{array}{r}
\int_{0}^{1} G(t, s) g\left(s,\left(I_{n-1} x\right)(s),\left(I_{n-1} y\right)(s), \ldots,\right. \\
\left.\left(I_{1} x\right)(s),\left(I_{1} y\right)(s), x(s), y(s)\right) d s
\end{array}
$$

is converged, and we have that

$$
\begin{array}{r}
\int_{0}^{1} G(t, s) g\left(s,\left(I_{n-1} u\right)(s),\left(I_{n-1} v\right)(s), \ldots,\right. \\
\left.\left(I_{1} u\right)(s),\left(I_{1} v\right)(s), u(s), v(s)\right) d s
\end{array}
$$

converges.

Define the operator $F: C(I) \times C(I) \rightarrow C(I)$ by

$$
\begin{array}{r}
F(u, v)(t)=\int_{0}^{1} G(t, s) \\
\times g\left(s,\left(I_{n-1} u\right)(s),\left(I_{n-1} v\right)(s), \ldots,\right. \\
\left.\left(I_{1} u\right)(s),\left(I_{1} v\right)(s), u(s), v(s)\right) d s, \\
\forall t \in I .
\end{array}
$$


Let

$$
\begin{gathered}
\left(A_{0} u\right)(t)=\int_{0}^{1}|G(t, s)|\left(K_{0} u\right)(s) d s, \\
\left(B_{0} v\right)(t)=\int_{0}^{1}|G(t, s)|\left(M_{0} v\right)(s) d s, \\
\left(A_{i} u\right)(t)=\int_{0}^{1}|G(t, s)|\left(K_{i}\left(I_{i} u\right)\right)(s) d s, \\
i=1,2, \ldots, n-1, \\
\left(B_{i} v\right)(t)=\int_{0}^{1}|G(t, s)|\left(M_{i}\left(I_{i} v\right)\right)(s) d s, \\
i=1,2, \ldots, n-1, \\
(A u)(t)=\left(A_{0} u+A_{1} u+\cdots+A_{n-1} u\right)(t), \\
(B v)(t)=\left(B_{0} v+B_{1} v+\cdots+B_{n-1} v\right)(t) .
\end{gathered}
$$

By (14) and (25), for any $u_{1}, u_{2}, v_{1}, v_{2} \in C(I), u_{1} \leq u_{2}, v_{1} \geq v_{2}$, we have

$$
\begin{aligned}
- & A\left(u_{2}-u_{1}\right)-B\left(v_{1}-v_{2}\right) \\
\leq & F\left(u_{1}, v_{1}\right)-F\left(u_{2}, v_{2}\right) \\
\leq & A\left(u_{2}-u_{1}\right)+B\left(v_{1}-v_{2}\right), \\
((A+B) u)(t) & \\
= & \int_{0}^{1}|G(t, s)|\left[K_{0} u+M_{0} u+K_{1}\left(I_{1} u\right)+M_{1}\left(I_{1} u\right)+\cdots\right. \\
& \left.\quad+K_{n-1}\left(I_{n-1} u\right)+M_{n-1}\left(I_{n-1} u\right)\right](s) d s \\
\leq & \left(\frac{K_{0}+M_{0}}{(n-2) !}+\frac{K_{1}+M_{1}}{(n-3) !}+\cdots+\frac{K_{n-3}+M_{n-3}}{1 !}\right. \\
& \left.+K_{n-2}+M_{n-2}+K_{n-1}+M_{n-1}\right) \cdot\|u\| h_{1}(t), \\
\left((A+B)^{m} u\right)(t) \quad & \left.\quad+\frac{K_{n-3}+M_{n-3}}{1 !}+K_{n-2}+M_{n-2}+M_{n-1}\right)^{m} \cdot \sup _{t \in J} e_{m}(t), \\
= & \int_{0}^{1}|G(t, s)|(A+B)(A+B)^{m-1}(u)(s) d s \\
\leq & \left(\frac{K_{0}+M_{0}}{(n-2) !}+\frac{K_{1}+M_{1}}{(n-3) !}+\cdots+\frac{K_{n-3}+M_{n-3}}{1 !}\right. \\
& \left.+K_{n-2}+M_{n-2}+K_{n-1}+M_{n-1}\right)^{m} \cdot\|u\| h_{m}(t), \\
\left\|(A+B)^{m}\right\| \leq\left(\frac{K_{0}+M_{0}}{(n-2) !}+\frac{K_{1}+M_{1}}{(n-3) !}+\cdots\right. & m, \ldots,
\end{aligned}
$$

this implies

$$
-(v+w) \leq u \leq v+w .
$$

Let

$$
\|u\|_{0}=\inf \{\|h\| \mid h \in P,-h \leq u \leq h\} .
$$

By (31), we know that $\|u\|_{0}$ is well defined for any $u \in C(I)$. It is easy to verify that $\|\cdot\|_{0}$ is a norm in $C(I)$. By (30)-(32), we get

$$
\|u\|_{0} \leq\|v+w\| \leq 2 \tau\|u\|, \quad \forall u \in C(I) .
$$

On the other hand, for any $h \in P$ which satisfies $-h \leq u \leq$ $h$, we have $0 \leq u+h \leq 2 h$; thus, $\|u\| \leq\|u+h\|+\|-h\| \leq$ $(2 N+1)\|h\|$, where $N$ denotes the normal constant of $P$. Since $h$ is arbitrary, we have

$$
\|u\| \leq(2 N+1)\|u\|_{0}, \quad \forall u \in C(I) .
$$

It follows from (33) and (34) that the norms $\|\cdot\|_{0}$ and $\|\cdot\|$ are equivalent. Now, for any $u, v \in C(I)$ and $h \in P$ which satisfies $-h \leq u-v \leq h$, let

$$
\begin{gathered}
u_{1}=\frac{1}{2}(u+v-h), \\
u_{2}=\frac{1}{2}(u-v+h), \\
u_{3}=\frac{1}{2}(-u+v+h),
\end{gathered}
$$

then $u \geq u_{1}, v \geq u_{1}, u-u_{1}=u_{2}, v-u_{1}=u_{3}, u_{2}+u_{3}=h$. 
It follows from (27) that

$$
\begin{gathered}
-A u_{2} \leq F(u, u)-F\left(u_{1}, u\right) \leq A u_{2}, \\
-A u_{3}-B u_{2} \leq F\left(v, u_{1}\right)-F\left(u_{1}, u\right) \leq A u_{2}+B u_{3}, \\
-B u_{3} \leq F\left(v, u_{1}\right)-F(v, v) \leq F u_{3}
\end{gathered}
$$

subtracting (37) from $(36)+(38)$, we obtain

$$
-(A+B) h \leq F(u, u)-F(v, v) \leq(A+B) h .
$$

Let $G(u)=F(u, u)$; then we have

$$
-(A+B) h \leq G(u)-G(v) \leq(A+B) h .
$$

As $A$ and $B$ are both positive linear bounded operators, so $A+B$ is a positive linear bounded operator, and therefore, $(A+B) h \in P$. Hence, by mathematical induction, it is easy to know that for natural number $k_{0}$ in (29), we have

$$
\begin{aligned}
-(A+B)^{k_{0}} h & \leq G^{k_{0}}(u)-G^{k_{0}}(v) \\
& \leq(A+B)^{k_{0}} h, \quad(A+B)^{k_{0}} h \in P ;
\end{aligned}
$$

since $(A+B)^{k_{0}} h \in P$, we see that

$$
\left\|G^{k_{0}}(u)-G^{k_{0}}(v)\right\|_{0} \leq\left\|(A+B)^{k_{0}}\right\|\|h\|,
$$

which implies by virtue of the arbitrariness of $h$ that

$$
\begin{aligned}
\left\|G^{k_{0}} u-G^{k_{0}} v\right\|_{0} & \leq\left\|(A+B)^{k_{0}}\right\|\|u-v\|_{0} \\
& \leq \beta^{k_{0}}\|u-v\|_{0} .
\end{aligned}
$$

By $0<\beta<1$, we have $0<\beta^{k_{0}}<1$. Thus, the Banach contraction mapping principle implies that $G^{k_{0}}$ has a unique fixed point $u^{*}$ in $C(I)$, and so $G$ has a unique fixed point $u^{*}$ in $C(I)$; by the definition of $G, F$ has a unique fixed point $u^{*}$ in $C(I)$; then, by Lemma $2, I_{n-1} u^{*}$ is the unique solution of (3). And, for any $u_{0} \in C(I)$, let $u_{m}=F\left(u_{m-1}, u_{m-1}\right)(m=1,2, \ldots)$; we have $\left\|u_{m}-u^{*}\right\|_{0} \rightarrow 0(k \rightarrow \infty)$. By the equivalence of $\|\cdot\|_{0}$ and $\|\cdot\|$ again, we get $\left\|u_{m}-u^{*}\right\| \rightarrow 0(m \rightarrow \infty)$. This completes the proof.

\section{Example}

In this paper, the results apply to a very wide range of functions, and we are following only one example to illustrate.

Consider the following $n$ th-order three-point boundary value problem:

$$
\begin{gathered}
u^{(n)}(t)+\left(S_{0} u\right)(t)+\left(S_{1} u^{\prime}\right)(t) \\
+k(t) \ln (3+|x(t)|), \quad t \in(0,1) \\
u(0)=u^{\prime}(0)=\cdots=u^{(n-2)}(0)=0 \\
u(1)=2 u\left(\frac{1}{2}\right)
\end{gathered}
$$

where $\left(S_{i} u^{(i)}\right)(t)=\int_{0}^{1} h_{i}(t, s) u^{(i)}(s) d s, h_{i}, k \in C(I \times I, \mathbb{R}), i=$ 0,1 .

Applying Theorem 4, we can find that (44) has a unique solution $I_{n} x^{*}(t) \in C^{(n)}(I)$ provided $\sup _{t, s \in I} \mid\left(h_{0}(t, s) /(n-2) !\right)+$ $\left(h_{1}(t, s) /(n-3) !\right)+(k(t) / 3(n-2) !) \mid<1$, and moreover, for any $u_{0} \in C(I)$, the iterative sequence

$$
\begin{aligned}
x_{m}(t)=\int_{0}^{1} G(t, s)[ & S_{0}\left(I_{n-1} x_{m-1}\right)(s) \\
& +S_{1}\left(I_{n-2} x_{m-1}\right)(s) \\
& \left.+k(s) \ln \left(3+\left|x_{m-1}(s)\right|\right)\right] d s
\end{aligned}
$$

$(m=1,2, \ldots)$ converges to $x^{*}$ uniformly for all $t$ in $I(m \rightarrow$ $\infty)$.

To see that, let

$$
\begin{aligned}
& G_{1}(t, s)= \begin{cases}-1+\frac{2^{n-2}}{2^{n-2}-1}\left[(1-s)^{n-1}-2\left(\frac{1}{2}-s\right)^{n-1}\right], & 0 \leq s \leq \frac{1}{2}, s \leq t, \\
\frac{2^{n-2}}{2^{n-2}-1}\left[(1-s)^{n-1}-2\left(\frac{1}{2}-s\right)^{n-1}\right], & 0 \leq t \leq s \leq \frac{1}{2}, \\
-1+\frac{2^{n-2}}{2^{n-2}-1}(1-s)^{n-1}, & \frac{1}{2} \leq s \leq t, \\
\frac{2^{n-2}}{2^{n-2}-1}(1-s)^{n-1}, & \frac{1}{2} \leq s, t \leq s,\end{cases} \\
& e_{1}^{*}(t)=\max \left\{\int_{0}^{1}\left|G_{1}(t, s)\right| d s, \int_{0}^{t} \int_{0}^{1}\left|G_{1}(s, x)\right| d x d s\right\} ;
\end{aligned}
$$

then $G_{1}(t, s)$ is Green's function of (44). It is easy to verify that $\left|G_{1}(t, s)\right| \leq 1$, and so $\rho\left(G_{1}\right) \geq\left(\sup _{t, s \in I} e_{1}^{*}(t)\right)^{-1} \geq 1$.

Let

$$
\begin{gathered}
g\left(t, u(t), v(t), u^{\prime}(t), v^{\prime}(t), \ldots, u^{(n-1)}(t), v^{(n-1)}(t)\right) \\
=\left(S_{0} u\right)(t)+\left(S_{1} u^{\prime}\right)(t)+k(t) \ln (3+|v(t)|), \\
\left(K_{i} u\right)(t)=H_{i}^{*} \int_{0}^{1} u(s) d s, \quad i=0,1, \\
\left(M_{0} v\right)(t)=\frac{K^{*}}{3} \int_{0}^{t} v(s) d s, \\
\left(M_{i} u\right)(t)=0, \quad i=1, \ldots, n-1, \\
u_{0}=v_{0}=0,
\end{gathered}
$$

where $H_{i}^{*}=\sup _{t, s \in I}\left|h_{i}(t, s)\right|(i=0,1), K^{*}=\sup _{t \in I}|k(t)|$; then it is easy to verify that all conditions in Theorem 4 are satisfied.

\section{Acknowledgments}

Peiguo Zhang and Lishan Liu were supported financially by the National Natural Science Foundation of China 
(11071141, 11371221), the Specialized Research Foundation for the Doctoral Program of Higher Education of China (20123705110001), the Program for Scientific Research Innovation Team in Colleges and Universities of Shandong Province, and the Project of Shandong Province Higher Educational Science and Technology Program (J11LA06, J13LI02). Yonghong $\mathrm{Wu}$ was supported financially by the Australian Research Council through an ARC Discovery Project grant.

\section{References}

[1] A. V. Bicadze and A. A. Samarskiǔ, "Some elementary generalizations of linear elliptic boundary value problems," Doklady Akademii Nauk SSSR, vol. 185, pp. 739-740, 1969.

[2] V. A. II'in and E. I. Moiseev, "Nonlocal boundary value problem of the first kind for a Sturm-Liouville operator in its differential and finite difference aspects," Differential Equations, vol. 23, pp. 803-810, 1987.

[3] V. A. II'in and E. I. Moiseev, "Nonlocal boundary value problem of the second kind for a Sturm-Liouville operator," Differential Equations, vol. 23, pp. 979-987, 1987.

[4] C. P. Gupta, "Solvability of a three-point nonlinear boundary value problem for a second order ordinary differential equation," Journal of Mathematical Analysis and Applications, vol. 168, no. 2, pp. 540-551, 1992.

[5] P. W. Eloe and B. Ahmad, "Positive solutions of a nonlinear $n$th order boundary value problem with nonlocal conditions," Applied Mathematics Letters, vol. 18, no. 5, pp. 521-527, 2005.

[6] X. Hao, L. Liu, and Y. Wu, "Positive solutions for nonlinear $n$ thorder singular nonlocal boundary value problems," Boundary Value Problems, vol. 2007, Article ID 74517, 2007.

[7] J. R. Graef and T. Moussaoui, "A class of $n$ th-order BVPs with nonlocal conditions," Computers \& Mathematics with Applications, vol. 58, no. 8, pp. 1662-1671, 2009.

[8] C. Pang, W. Dong, and Z. Wei, "Green's function and positive solutions of $n$th order $m$-point boundary value problem," Applied Mathematics and Computation, vol. 182, no. 2, pp. 12311239, 2006.

[9] J. Yang and Z. Wei, "Positive solutions of $n$th order $m$-point boundary value problem," Applied Mathematics and Computation, vol. 202, no. 2, pp. 715-720, 2008.

[10] Y. Guo, Y. Ji, and J. Zhang, “Three positive solutions for a nonlinear $n$ th-order $m$-point boundary value problem," Nonlinear Analysis: Theory, Methods \& Applications, vol. 68, no. 11, pp. 3485-3492, 2008.

[11] M. ur Rehman and R. A. Khan, "Existence and uniqueness of solutions for multi-point boundary value problems for fractional differential equations," Applied Mathematics Letters, vol. 23, no. 9, pp. 1038-1044, 2010.

[12] M. El-Shahed and J. J. Nieto, "Nontrivial solutions for a nonlinear multi-point boundary value problem of fractional order," Computers \& Mathematics with Applications, vol. 59, no. 11, pp. 3438-3443, 2010.

[13] G. Zhang and J. Sun, "Positive solutions of $m$-point boundary value problems," Journal of Mathematical Analysis and Applications, vol. 291, no. 2, pp. 406-418, 2004.

[14] M. Feng and W. Ge, "Existence results for a class of $n$th order $m$-point boundary value problems in Banach spaces," Applied Mathematics Letters, vol. 22, no. 8, pp. 1303-1308, 2009.

[15] X. Hao, L. Liu, and Y. Wu, "On positive solutions of an $m$-point nonhomogeneous singular boundary value problem," Nonlinear
Analysis: Theory, Methods \& Applications, vol. 73, no. 8, pp. 2532-2540, 2010.

[16] W. Jiang, "Multiple positive solutions for $n$ th-order $m$-point boundary value problems with all derivatives," Nonlinear Analysis: Theory, Methods \& Applications, vol. 68, no. 5, pp. 1064-1072, 2008.

[17] J. R. Graef and B. Yang, "Positive solutions to a multi-point higher order boundary value problem," Journal of Mathematical Analysis and Applications, vol. 316, no. 2, pp. 409-421, 2006.

[18] M. Zhang, Y. Yin, and Z. Wei, "Positive solution of singular higher-order $m$-point boundary value problem with nonlinearity that changes sign," Applied Mathematics and Computation, vol. 201, no. 1-2, pp. 678-687, 2008.

[19] J. R. Graef, L. Kong, and B. Yang, "Existence of solutions for a higher order multi-point boundary value problem," Results in Mathematics, vol. 53, no. 1-2, pp. 77-101, 2009.

[20] Y. Ji and Y. Guo, “The existence of countably many positive solutions for some nonlinear $n$th order $m$-point boundary value problems," Journal of Computational and Applied Mathematics, vol. 232, no. 2, pp. 187-200, 2009.

[21] X. Zhang, M. Feng, and W. Ge, "Multiple positive solutions for a class of $m$-point boundary value problems," Applied Mathematics Letters, vol. 22, no. 1, pp. 12-18, 2009.

[22] J. Zhao and W. Ge, "Existence results of $m$-point boundary value problem of Sturm-Liouville type with sign changing nonlinearity," Mathematical and Computer Modelling, vol. 49, no. 5-6, pp. 946-954, 2009.

[23] S. Liang and J. Zhang, "Existence of countably many positive solutions of $n$ th-order $m$-point boundary value problems," Journal of Computational and Applied Mathematics, vol. 224, no. 2, pp. 527-537, 2009.

[24] H. Su and X. Wang, "Positive solutions to singular semipositone $m$-point $n$-order boundary value problems," Journal of Applied Mathematics and Computing, vol. 36, no. 1-2, pp. 187-200, 2011.

[25] J. Henderson and R. Luca, "Existence and multiplicity for positive solutions of a multi-point boundary value problem," Applied Mathematics and Computation, vol. 218, no. 21, pp. 10572-10585, 2012.

[26] P. Zhang, "Iterative solutions of singular boundary value problems of third-order differential equation," Boundary Value Problems, vol. 2011, Article ID 483057, 10 pages, 2011.

[27] D. Guo, Semi-Ordered Method in Nonlinear Analysis, Shandong Scientific Technical Press, Jinan, China, 2000, Chinese.

[28] D. Guo and V. Lakshmikantham, Nonlinear Problems in Abstract Cones, Academic Press, New York, NY, USA, 1988.

[29] D. Guo, V. Lakshmikantham, and X. Liu, Nonlinear Integral Equations in Abstract Spaces, vol. 373 of Mathematics and Its Applications, Kluwer Academic Publishers, Dordrecht, The Netherlands, 1996. 


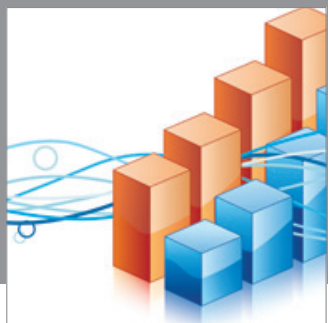

Advances in

Operations Research

mansans

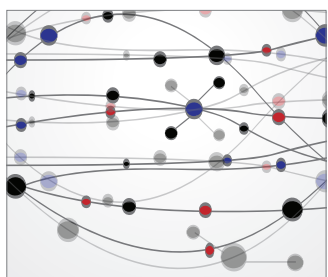

The Scientific World Journal
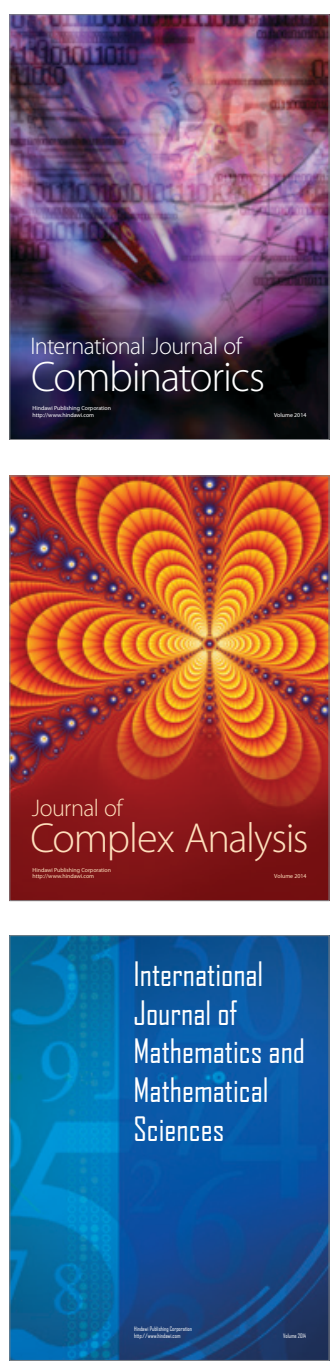
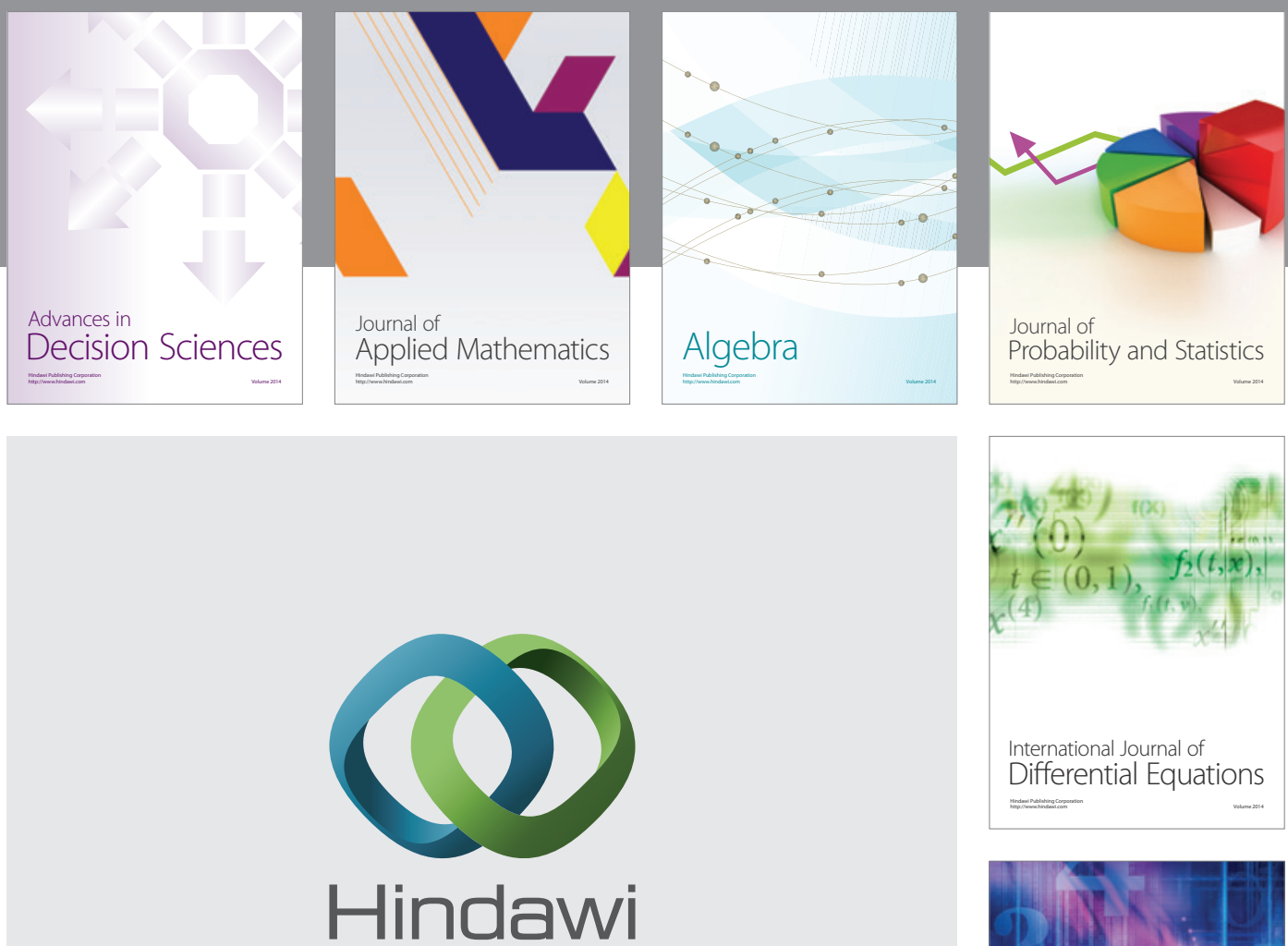

Submit your manuscripts at http://www.hindawi.com
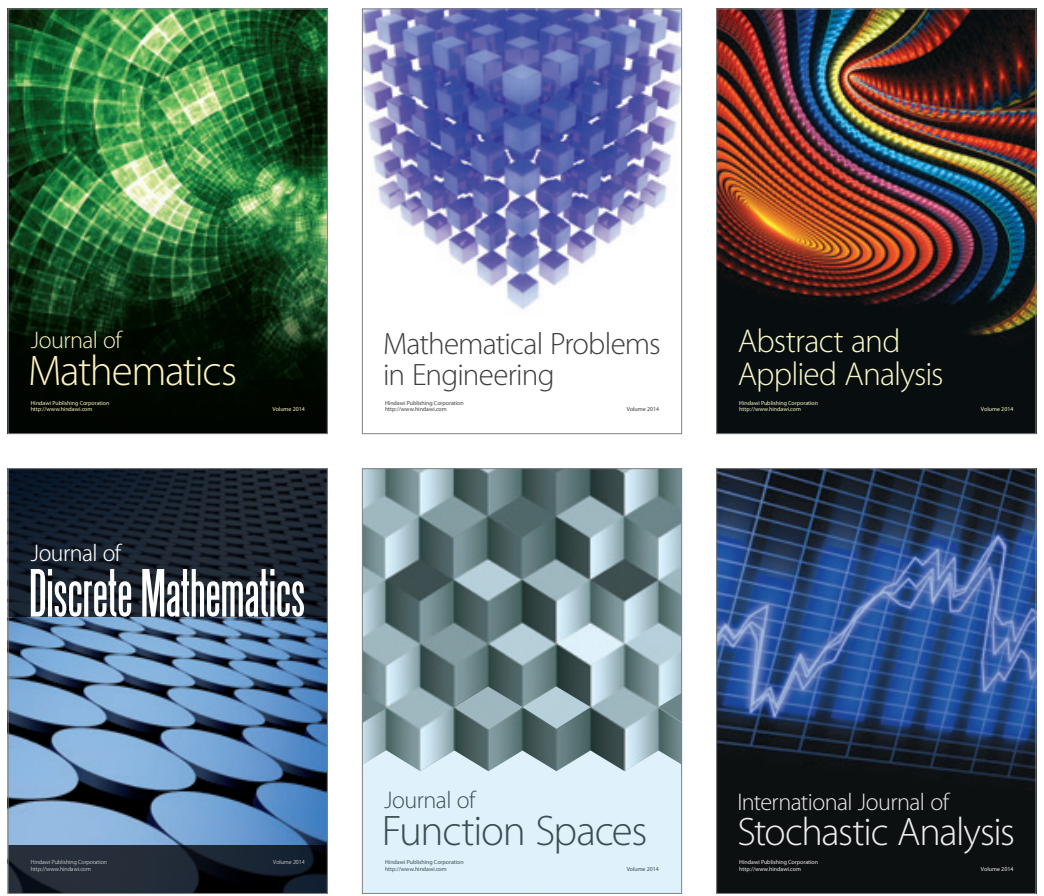

Journal of

Function Spaces

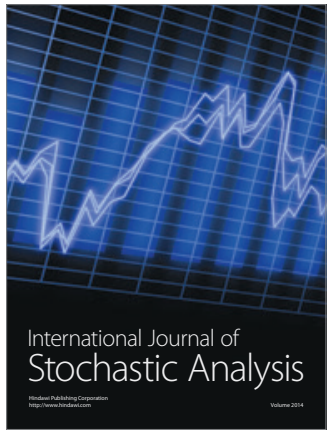

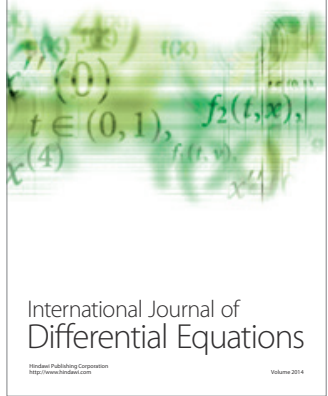
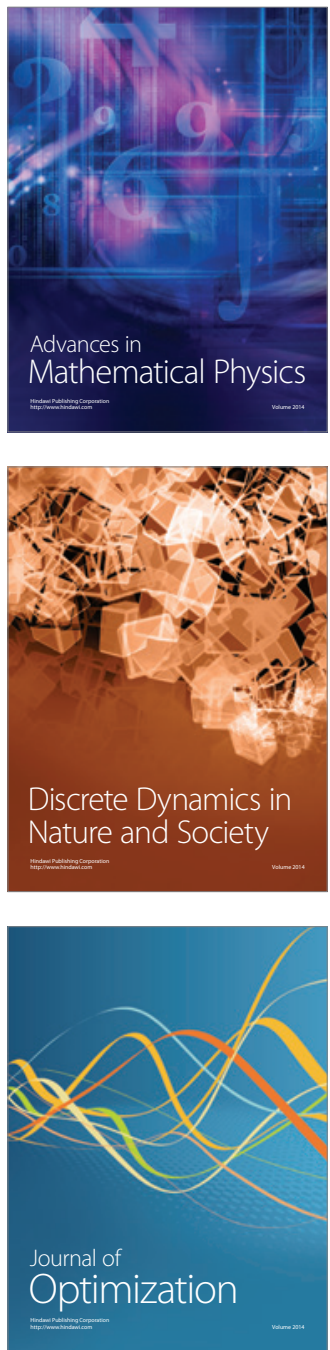